\title{
Co-Evaporated p-i-n Perovskite Solar Cells Beyond 20\% Efficiency: Impact of Substrate Temperature and Hole- Transport Layer
}

\author{
Marcel Roß ${ }^{1 *}$, Lidón Gil-Escrig ${ }^{1}$, Amran Al-Ashouri ${ }^{1}$, Philipp Tockhorn ${ }^{3}$, Marko Jošt ${ }^{1,2}$, Bernd Rech ${ }^{3,4}$ \\ and Steve Albrecht ${ }^{1,4 *}$ \\ ${ }^{1}$ Young Investigator Group Perovskite Tandem Solar Cells, Helmholtz-Zentrum Berlin, Kekuléstraße 5, 12489 Berlin, \\ Germany \\ ${ }^{2}$ University of Ljubljana, Faculty of Electrical Engineering, Tržaška 25, 1000 Ljubljana \\ ${ }^{3}$ Institute for Silicon Photovoltaics, Helmholtz-Zentrum Berlin, Kekuléstraße 5, 12489 Berlin, Germany \\ ${ }^{4}$ Faculty of Electrical Engineering and Computer Science, Technical University Berlin, Marchstraße 23, 10587 Berlin, \\ Germany \\ *Corresponding authors: marcel.ross@helmholtz-berlin.de, steve.albrecht@helmholtz-berlin.de
}

\begin{abstract}
For methylammonium lead iodide perovskite solar cells prepared by co-evaporation, power conversion efficiencies of over $20 \%$ have been already demonstrated, however, so far only in n-i-p configuration. Currently, the overall major challenges are the complex evaporation characteristics of organic precursors that strongly depend on the underlying charge selective contacts and the insufficient reproducibility of the co-evaporation process. To ensure a reliable co-evaporation process, it is important to identify the impact of different parameters in order to develop a more detailed understanding. In this work, we study the influence of substrate temperature, underlying hole transporting material (polymer PTAA versus self-assembling monolayer molecule $\mathrm{MeO}-2 \mathrm{PACz}$ ) and perovskite precursor ratio on the morphology, composition and performance of co-evaporated $\mathrm{p}-\mathrm{i}-\mathrm{n}$ perovskite solar cells. We first analyse the evaporation of pure precursor materials and show that the adhesion of methylammonium iodide (MAI) is significantly reduced with increased substrate temperature, while it remains almost unaffected for lead iodide $\left(\mathrm{PbI}_{2}\right)$. This substrate temperature-dependent evaporation behaviour of MAI is also transferred to the co-evaporation process and can directly influence the perovskite composition. We demonstrate that the optimal substrate temperature window for perovskite deposition is close to room temperature. At high temperature not enough MAI for precise stoichiometry is incorporated even with very high MAI rates While at temperatures below $-25{ }^{\circ} \mathrm{C}$ the conversion of $\mathrm{MAI}$ with $\mathrm{PbI}_{2}$ is inhibit and an amorphous yet unreacted film is formed. We observe that perovskite composition and morphology vary widely between the organic hole-transport layer (HTLs) PTAA and MeO-2PACz. For all substrate temperatures $\mathrm{MeO}-2 \mathrm{PACz}$ enables higher solar cell PCEs than PTAA. Through the combination of vapourdeposited perovskites and self-assembled monolayer, we achieve a stabilised power conversion efficiency of $20.6 \%$, which is the first reported PCE above $20 \%$ for evaporated perovskite solar cells in $\mathrm{p}-\mathrm{i}-\mathrm{n}$ architecture.
\end{abstract}




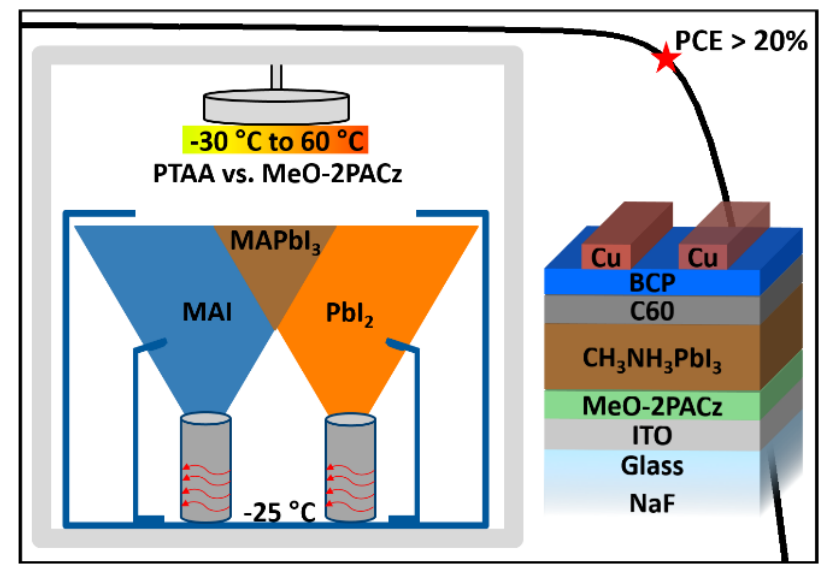

Figure: TOC

In the past 7 years, the power conversion efficiencies of perovskite solar cells (PSCs) raised from $14 \%$ to over $25 \%$ due to the outstanding optoelectronic properties of the perovskite absorber, the continuous development of the fabrication process, and the comprehensive research. ${ }^{1}$ With power conversion efficiencies (PCE) above other thin film technologies and values approaching those of crystalline silicon, ${ }^{2}$ the enormous potential of hybrid organicinorganic perovskite solar cells has been demonstrated. Perovskites defined by the general formula $\mathrm{ABX}_{3}$ consist of a three-dimensional network of corner sharing octahedrons. ${ }^{3}$ Typical perovskite absorbers contain a heavy metal in oxidation state $+\mathrm{II}\left(\mathrm{B} \bumpeq \mathrm{Pb}^{2+}, \mathrm{Sn}^{2+}\right)$, a mixture of various cations $\left(\mathrm{A} \hat{=}\right.$ methylammonium, formamidinium, $\left.\mathrm{Cs}^{2+}, \mathrm{Rb}^{2+}\right)$ and different halide anions $\left(\mathrm{X} \triangleq \mathrm{I}^{-}, \mathrm{Br}^{-}, \mathrm{Cl}^{-}\right) .{ }^{4}$ The predominant hybrid organic-inorganic perovskite composition is methylammonium lead iodide $\left(\mathrm{MAPbI}_{3}\right)$. $\mathrm{MAPbI}_{3}$ gained attention due to its direct band gap, the high absorption coefficient ${ }^{5}$ and the long charge carrier diffusion lengths. ${ }^{6}$ Besides their excellent optoelectronic properties, ${ }^{7-8}$ the possibility to easily tune the band gap ${ }^{9}$ is especially attractive for the use of perovskites in tandem solar cells. Using tandem solar cell architectures, combining complementary absorbers such as crystalline silicon and perovskite, the practical reached PCE limit of single solar cells has been overcome. ${ }^{1,10-11}$

Apart from the high PCE potential, the simplicity of preparation and the variety of deposition methods is a great advantage of PSCs. ${ }^{12-14}$ Currently, most perovskite thin films are produced by solution-based processes, ${ }^{15}$ primarily by spin coating. These methods waste a large amount of hazardous solvents and are not easily scalable. Vacuum deposition techniques, widely used in coating industry, offer several advantages. ${ }^{16}$ It is possible to conformably cover different textures and homogeneously coat on large substrates. ${ }^{17}$ Furthermore, it enables an accurate control of layer thicknesses, ${ }^{18}$ which is of particular interest for achieving current matching in tandem solar cells. ${ }^{19}$ All in all, the versatility of deposition methods for perovskites makes the material highly attractive, whereby techniques like spin coating are well suited for the lab-based material screening and processes such as co-evaporation or printing are also suitable for industrial relevant large areas.

$\mathrm{MAPbI}_{3}$ films prepared by vacuum deposition usually show, with a dimension of around $100 \mathrm{~nm}$, smaller grain sizes in comparison to spin coated films. ${ }^{13,}{ }^{20}$ While solution-based $\mathrm{MAPbI}_{3}$ crystallises at room temperature in the tetragonal phase, it is possible to obtain a cubic phase at room temperature by adjusting the deposition rates during the co-evaporation process. ${ }^{20}$ This may also explain why the band gap of $\mathrm{MAPbI}_{3}$ prepared by co-evaporation is often larger, compared to the band gab of spin-coated $\mathrm{MAPbI}_{3} .{ }^{21} \mathrm{In}$ addition to $\mathrm{MAPbI}_{3}$ also more complex compositions, such as triple cation perovskite, ${ }^{16}$ Sn-based perovskites, ${ }^{22}$ and even lower dimensional phenethylammonium lead iodide absorbers, ${ }^{23}$ can be prepared by coevaporation. 
Although PCEs of more than $20 \%{ }^{24-26}$ have already been achieved with vacuum-processed perovskites for $n-i-p$ architectures, the utilisation of this technology in the community is still limited due to the challenging process control for organic materials and the lack of reproducibility. ${ }^{27}$ The importance of a fundamental understanding of material properties such as density ${ }^{28}$ or purity ${ }^{29}$ of methylammonium iodide (MAI) for a stable evaporation process, was shown in recent publications. A parameter which is well studied for a variety of vacuum deposition methods and materials is the substrate temperature. The importance of this parameter can be seen in models like the structural zone model developed by Movchan and Demchishin. ${ }^{30}$ This model allows a prediction of qualitative layer properties as a function of the normalised substrate temperature in the evaporation process. For the hybrid deposition process of MAI and $\mathrm{PbI}_{2}$ a first publication reported a reduced incorporation of MAI into the perovskite at elevated substrate temperatures. ${ }^{31}$ Bækbo et al. studied the evaporation behaviour of MAI and showed that the sticking of MAI to a lead chloride covered sensor decreases when the sensor temperature was changed from $65^{\circ} \mathrm{C}$ to $85^{\circ} \mathrm{C} .{ }^{32}$ Both, Kottokkaran et al. ${ }^{33}$ and Lohmann et al. $^{34}$ studied the influence of substrate temperature during the co-evaporation process on perovskite film morphology. Remarkably, Kottokkaran et al. obtained larger average grain sizes with elevated substrate temperatures $\left(75^{\circ} \mathrm{C}\right)$ and Lohmann et al. reported increased grain sizes for depositions with substrate temperatures below $0{ }^{\circ} \mathrm{C}$. In contrast to the variety of publications for solution based depositions, ${ }^{35-37}$ the impact of the substrate temperature over a large temperature range has not been analysed in detail so far.

In a direct comparison between n-i-p and p-i-n architecture Momblona et al. demonstrated a reduced PCE for $\mathrm{p}-\mathrm{i}-\mathrm{n}$ solar cells, which is attributed to a barrier for hole extraction at the p-contact. ${ }^{24}$ For evaporated perovskite solar cells power conversion efficiencies of over $20 \%$ have so far only been realised in the n-i-p structure. ${ }^{24-26}$ Nevertheless we use the p-i-n architecture, lately becoming increasingly important and being utilised as top-cell configuration for the most efficient tandem solar cells. ${ }^{11,38-41}$ In this configuration, the perovskite is deposited on top of the hole-transporting layer (HTL). Since it has been shown that the initial growth of co-evaporated perovskite can be influenced by the choice of the substrate, ${ }^{42}$ we study the impact of the substrate temperature for two different HTLs. We compare the p-type polymeric HTL poly[bis(4-phenyl)(2,4,6-trime-thylphenyl)amine (PTAA) $)^{43-44}$ with the self-assembled monolayer [2-(3,6-dimethoxy-9H-carbazol-9-yl)ethyl]phosphonic acid (MeO-2PACz). ${ }^{45}$ This molecule is able to covalently bind through its phosponic acid anchoring group to ITO and is forming a simple but effective hole-selective contact. ${ }^{45-46}$ Owing to the self-limiting monolayer forming process, this HTL can be prepared by different methods within a wide processing window even on rough surfaces.

In this study we analyse in detail the influence of the substrate temperature on the evaporation process for both the pure layers of perovskite precursor materials $\mathrm{MAI}$ and $\mathrm{PbI}_{2}$ as well as for co-evaporated methylammonium lead iodide $\left(\mathrm{MAPbI}_{3}\right)$ films. We demonstrate the influence of the substrate temperature on the solar cell PCE using the two different HTLs. We perform our experiments in a large temperature range and quantify the upper and lower temperature limits for high quality perovskite film deposition. Furthermore, we show that the choice of the HTL not only influences the PCE of the solar cell but also the optimal conditions for perovskite deposition in terms of substrate temperature and precursor ratio. With these insights into the impact of the substrate temperature and optimised HTL, we achieve a stabilised power conversion efficiency of $20.6 \%$ for co-evaporated p-i-n perovskite solar cells. 


\section{Pure precursor layers}

In a co-evaporation process, it is necessary to correctly determine the evaporation rate of each material to precisely control the film stoichiometry. The difference between the actual thickness on the substrate in comparison to the thickness displayed at the quartz crystal microbalances (QCM sensor) is referred as tooling factor. ${ }^{47}$ In first approximation, the tooling factor is considered as a geometric correction factor to compensate for the difference in position between sensor and substrate relative to the source. In addition, the tooling factor, which is sometimes also called calibration factor, can strongly depend on the adhesion of the material to the substrate. In order to analyse the adhesion of the precursor materials to get more insights into the evaporation process, we quantify the tooling factors for the pure precursors first.

Figure 1 displays the tooling factor for the precursor materials, $\mathrm{PbI}_{2}$ and $\mathrm{MAI}$, as a function of substrate temperature. This was estimated by measuring the average film thickness on the quartz glass substrate versus the thickness of the material deposited directly on the QCM. The temperature of the QCM sensor was kept constant for all experiments. As both materials tend to form layers with high roughness (root mean square roughness above $40 \mathrm{~nm}$ for all films), the average thickness of all films was obtained by removing some of the material with a scalpel and measuring an atomic force microscope (AFM) image of the resulting scratch. AFM images and details on the measurement as well as the tooling factors on PTAA and MeO-2PACz can be found in the Supporting Information. This technique allows us to directly measure the evolution of condensed mass on the substrate at different temperatures.

While the tooling factor of $\mathrm{PbI}_{2}$ is almost constant over a temperature range of $90 \mathrm{~K}$ from $-30{ }^{\circ} \mathrm{C}$ to $60{ }^{\circ} \mathrm{C}$, the adhesion of MAI is lowered significantly by over $70 \%$ in the same substrate temperature range. Due to the high vapour pressure, MAI tends to re-evaporate from the substrate at elevated substrate temperatures. Although the distance between sensor and crucible is the same for the two materials, the tooling factors differ widely. In general, the tooling factor of MAI is significantly lower compared to $\mathrm{PbI}_{2}$ and is strongly influenced by the temperature of the substrate.

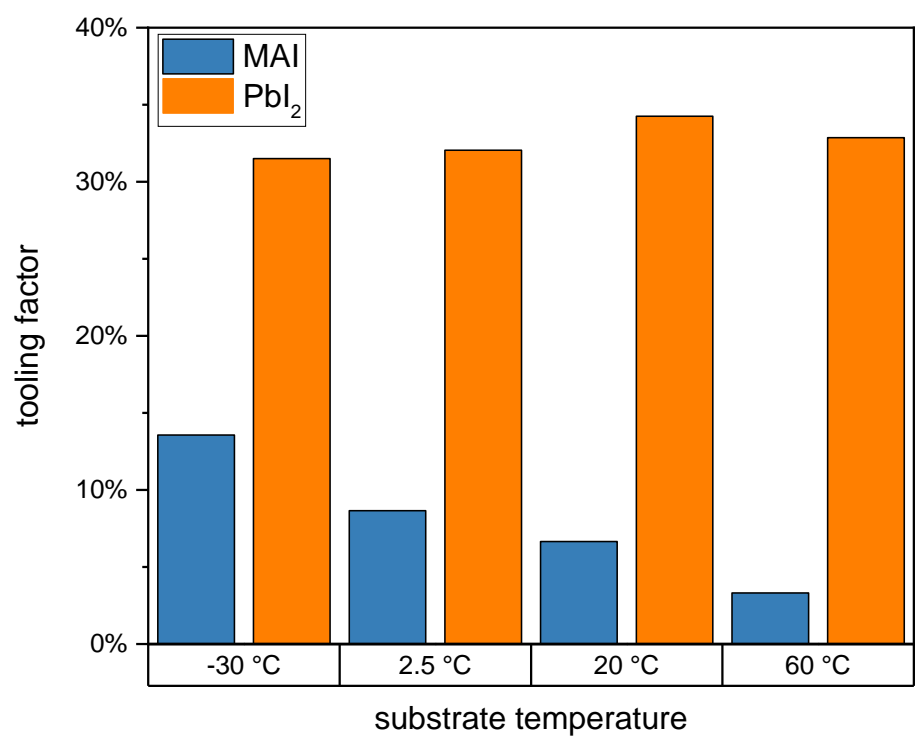

Figure 1: Correlation between substrate temperature and tooling factor (substrate film thickness versus the thickness deposited directly on the QCM) for MAI (blue) and $\mathrm{PbI}_{2}$ (orange) pure layers deposited on quartz glass. All films were deposited under the same evaporation conditions, such as base pressure and evaporation rate. 
To further understand how the substrate temperature influences the evaporation of the precursor materials, the morphology of the individual $\mathrm{PbI}_{2}$ and MAI layers was investigated. Figure 2 a) and $b$ ) show the scanning electron microscope (SEM) top view images of the pure $\mathrm{PbI}_{2}$ films prepared at different substrate temperatures on the HTLs PTAA and MeO-2PACz. For $\mathrm{PbI}_{2}$, the morphology is comparable for all films prepared. The nanoflakes ${ }^{48}$ characteristic for evaporated lead iodide films are present independently of the substrate temperature and the HTL used (see Supporting Information for images of the full temperature series). In contrast to this, the morphology for MAI films and the coverage is affected by the substrate temperature as presented using different HTLs in Figure 2, PTAA in c) and for MeO-2PACz in d). With elevated temperature, the grains become smaller and change their shape from elongated to round. Interestingly, while the morphology is similar at low temperature between PTAA and $\mathrm{MeO}-2 \mathrm{PACz}$, it differs at higher temperature between the HTLs. This morphology analysis confirms that the evaporation behaviour of MAI is highly dependent on substrate temperature while for $\mathrm{PbI}_{2}$ it is rather unaffected. It also reveals the high roughness of the materials and explains that only an average layer thickness of MAI and $\mathrm{PbI}_{2}$ on the substrate can be determined. It illustrates that thickness measurements that are strongly influenced by surface roughness or measure the layer thickness only at one point can lead to an incorrect determination of the tooling factor. As the tooling factor directly influences the measured evaporation rate, an incorrect tooling factor can consequently lead to a wrong estimation of the stoichiometry. Although almost all publications reporting vacuum based perovskites deposition use QCMs to measure the rate, ${ }^{27,29,33-34,49-52}$ only very few mention the determination of the tooling factor.

a)

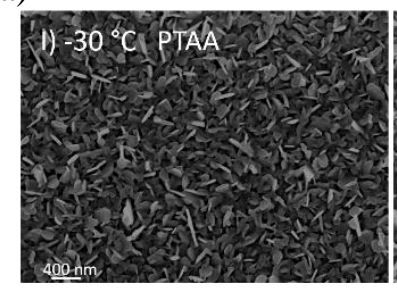

c)

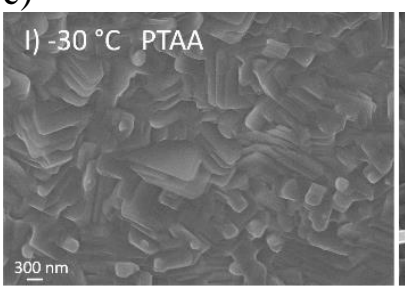

d)

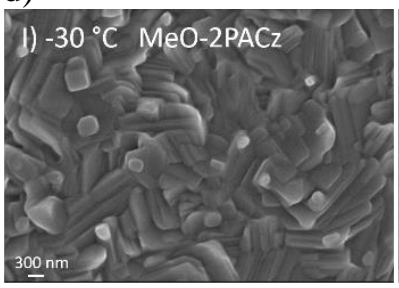

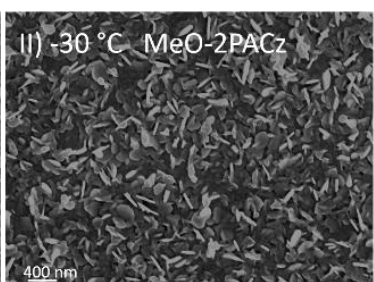

b)
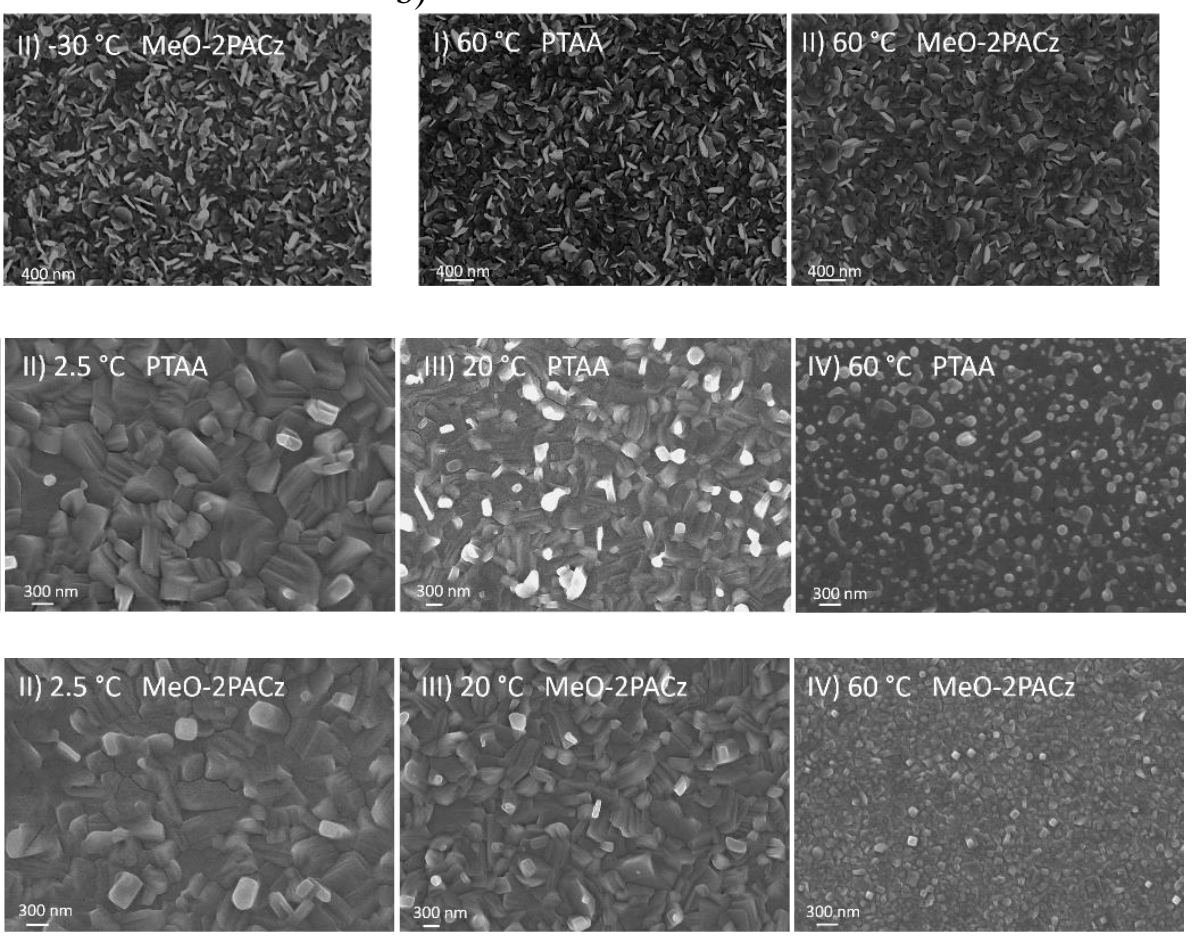

Figure 2: $\mathrm{SEM}$ top view images to observe the film morphology of a) $\mathrm{PbI}_{2}$ films deposited at low temperature on PTAA and MeO-2PACz; b) $\mathrm{PbI}_{2}$ layers on PTAA and MeO-2PACz evaporated at $60^{\circ}$ substrate temperature; c) MAI films on PTAA deposited with increasing substrate temperature from I to IV; d) MAI films on MeO-2PACz deposited at different substrate temperatures. 


\section{Co-Evaporation}

To investigate if the observed behaviour of the precursor materials is also important in the co-evaporation process, $\mathrm{MAPbI}_{3}$ perovskite films were deposited at different substrate temperatures. For all films a MAI rate of $3.2 \AA^{-1}$ and a $\mathrm{PbI}_{2}$ rate of $1.4 \AA^{-1}$ was used. A tooling factor of $100 \%$ was chosen for both MAI and $\mathrm{PbI}_{2}$, which allows a direct reading of the rate ratio of the two materials and simplifies the comparison between experiments with different substrate temperatures. Figure 3a presents the X-ray diffraction patterns (XRD) of these $\mathrm{MAPbI}_{3}$ films on PTAA. Only at room temperature $\left(20^{\circ} \mathrm{C}\right)$, a pure $\mathrm{MAPbI}_{3}$ - phase is present. With higher substrate temperature, an additional $\mathrm{PbI}_{2}$ phase at $2 \theta=12.7^{\circ}$ can be observed. For films deposited at lower substrate temperatures such as $2.5^{\circ} \mathrm{C}$, features of a MAI-phase at $2 \theta=9.8^{\circ}$ can be detected. Interestingly, besides the phase composition, the intensity distribution of the characteristic $\mathrm{MAPbI}_{3}$-reflexes changes with the substrate temperature as well, which indicates differences in the preferred orientation between the films. X-ray diffraction patterns of $\mathrm{MAPbI}_{3}$ films on $\mathrm{MeO}-2 \mathrm{PACz}$, showing a similar trend and evaporated $\mathrm{MAI}$ and $\mathrm{PbI}_{2}$ pure films as reference can be found in the Supporting Information. Although the relative peak area of the characteristic reflexes, displayed in Figure 3b, cannot be directly transferred into composition because of possible preferential orientations in thin films, there is a clear trend that with increasing substrate temperature significantly less MAI is incorporated into the film.

Overall, even at a constant rate ratio, the composition of the resulting perovskite material can be changed by the substrate temperature. This effect can be used to deliberately influence the composition of the film, but can also cause problems with reproducibility if the temperature is not constantly controlled.

These results are in line with the change in tooling factor observed for the precursor materials. Since the tooling factor of $\mathrm{PbI}_{2}$ is rather constant in the investigated temperature range and the tooling factor of MAI changes drastically, the ratio between MAI and $\mathrm{PbI}_{2}$ shifts with the temperature as well. Although the trends of the tooling factor observed for the individual layers of single source evaporation can be adapted to the co-evaporation process, the absolute values cannot be directly transferred. While according to the tooling factors a paired rate of $1.4 \AA \mathrm{s}^{-1}$ $\mathrm{PbI}_{2}$ and $5.3 \AA^{-1} \mathrm{~s}^{-1} \mathrm{MAI}$ should result in stoichiometric $\mathrm{MAPbI}_{3}$ perovskites at $20{ }^{\circ} \mathrm{C}$ on PTAA, however, the XRD pattern in Figure 3a shows that a pure $\mathrm{MAPbI}_{3}$ phase (therefore considered as stoichiometric) is obtained with a rate ratio of $1.4 \AA \mathrm{s}^{-1} \mathrm{PbI}_{2}$ to $3.2 \AA \mathrm{s}^{-1}$ instead. With the tooling factors determined for the pure materials, the resulting difference in stoichiometry was calculated in Table 1a. From the tooling factor of the pure precursors, one would expect a 0.61:1 molar ratio of MAI to $\mathrm{PbI}_{2}$, but the XRD pattern in Figure 3a shows a 1:1 molar ratio instead. This difference in stoichiometry can also be expressed in terms of a modified tooling factor of MAI, as shown in Table 1b. Under the assumption that a stoichiometric perovskite film is formed at a rate ratio of $3.2 \AA^{-1} \mathrm{MAI}$ to $1.4 \AA^{-1} \mathrm{~s}^{-1} \mathrm{PbI}_{2}$, as indicated by the XRD pattern in Figure 3a, the tooling factor of MAI increases almost two-fold from $7.9 \%$ for pure layers to $13 \%$ in the co-evaporation. This result is in good agreement with the findings of Bækbo et al., describing an enhanced adhesion of MAI to $\mathrm{PbCl}_{2}$-covered surface compared to pre-existing MAI layers ${ }^{32}$. Apparently, the tooling factors of $\mathrm{MAI}$ and $\mathrm{PbI}_{2}$ in the co-evaporation process are different from the tooling factors of the individually deposited pure precursor materials. 
Table 1: a) Calculation of the difference in stoichiometry when directly transferring the tooling factors of MAI and $\mathrm{PbI}_{2}$ pure precursor layers to the co-evaporation process. b) Estimation of the tooling factor for the materials in the co-evaporation process when assuming a 1 to 1 molar ratio between $\mathrm{MAI}$ and $\mathrm{PbI}_{2}$.

\begin{tabular}{|l|c|c|}
\hline a) & MAI & $\mathrm{PbI}_{2}$ \\
rate $[\AA / \mathrm{s}]$ & 3.2 & 1.4 \\
density $\left[\mathrm{g} / \mathrm{cm}^{3}\right]$ & 2.95 & 6.16 \\
tooling factor $[\%]$ & 7.9 & 41.7 \\
\hline molar ratio MAI to $\mathbf{P b I}_{2}$ & 0.61 to 1 \\
\hline
\end{tabular}

\begin{tabular}{|l|c|c|}
\hline b) & MAI & $\mathrm{PbI}_{2}$ \\
rate $[\AA / \mathrm{s}]$ & 3.2 & 1.4 \\
density $\left[\mathrm{g} / \mathrm{cm}^{3}\right.$ ] & 2.95 & 6.16 \\
molar ratio MAI to $\mathrm{PbI}_{2}$ & \multicolumn{2}{|c|}{1 to 1} \\
\hline \hline tooling factor $[\%]$ & 13 & 41.7 \\
\hline
\end{tabular}

In summary, an increased substrate temperature in the analysed range leads to a lower adhesion of MAI for both the evaporation of the pure precursor but also co-evaporated perovskite layers. However, the absolute tooling factor differs between evaporation of the pure materials and the co-evaporation. In the co-evaporation the adhesion of the MAI is higher and therefore lower MAI rates than expected are required for the deposition of stoichiometric $\mathrm{MAPbI}_{3}$.

In addition to the substrate temperature, the choice of substrate can also influence the coevaporation process. Figure 3c shows a direct comparison of the XRD pattern between films deposited at $20^{\circ} \mathrm{C}$ on PTAA and MeO-2PACz. Although both films are produced in the same evaporation process, and consequently under exactly the same evaporation conditions, surprisingly a different phase composition can be observed in XRD. While on PTAA a pure $\mathrm{MAPbI}_{3}$ phase is present, an additional $\mathrm{PbI}_{2}$ phase can be identified when using $\mathrm{MeO}-2 \mathrm{PACz}$ as HTL. These films were further analysed with scanning electron microscopy (SEM) as displayed in Figure 3d. A strong difference in morphology is also visible in SEM cross view. While films on PTAA show larger grains with similar width and height, the morphology on $\mathrm{MeO}-2 \mathrm{PACz}$ is characterised by smaller but longer columnar orientated grains. Morphology and XRD pattern indicate that the perovskite deposition on PTAA and MeO-2PACz is dominated by different growth mechanisms. This means that the hole-transport material can not only influence the morphology but has also an impact on the composition of the resulting perovskite material. Although it has already been demonstrated that the initial growth between metal oxide and organic HTLs differs ${ }^{42}$, it is remarkable that there are significant differences in morphology and composition between the two organic HTLs utilised here. 
a)

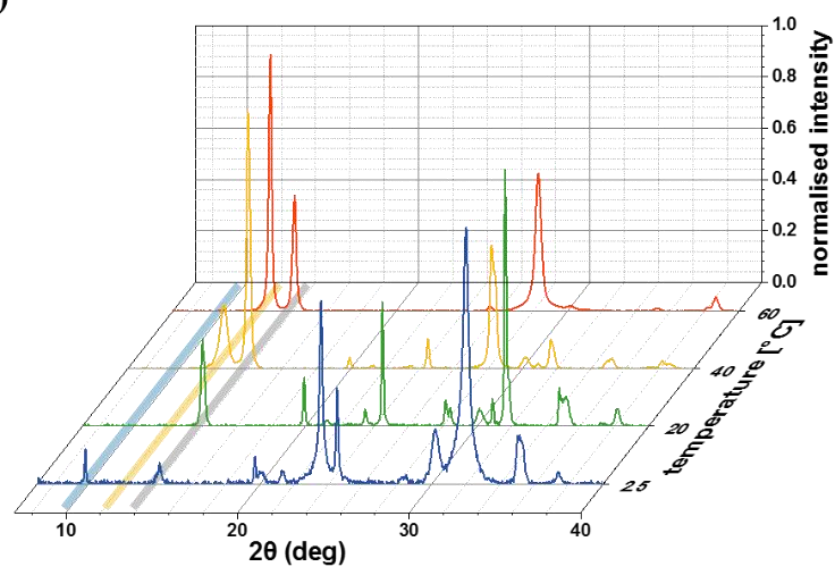

c)

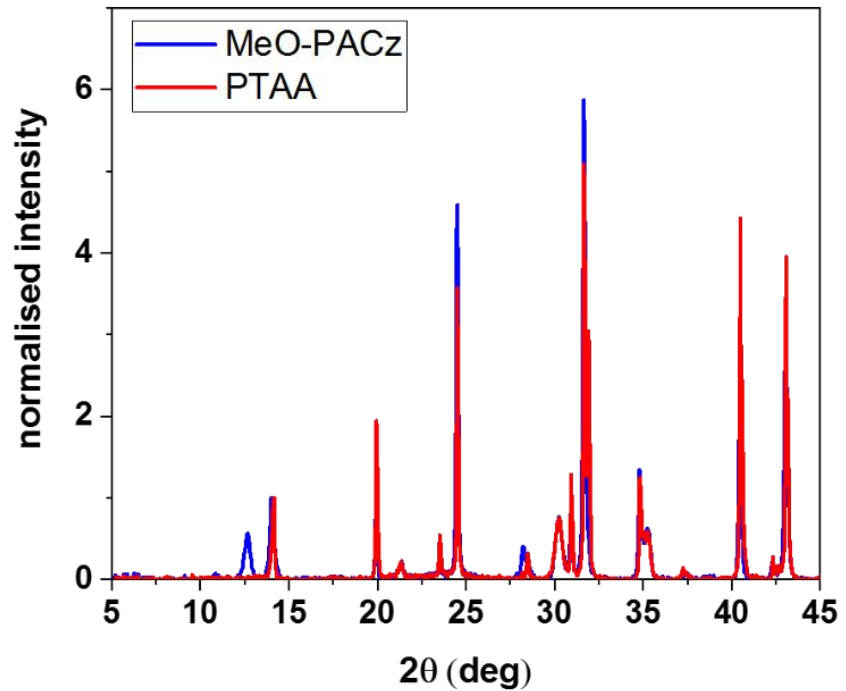

b)

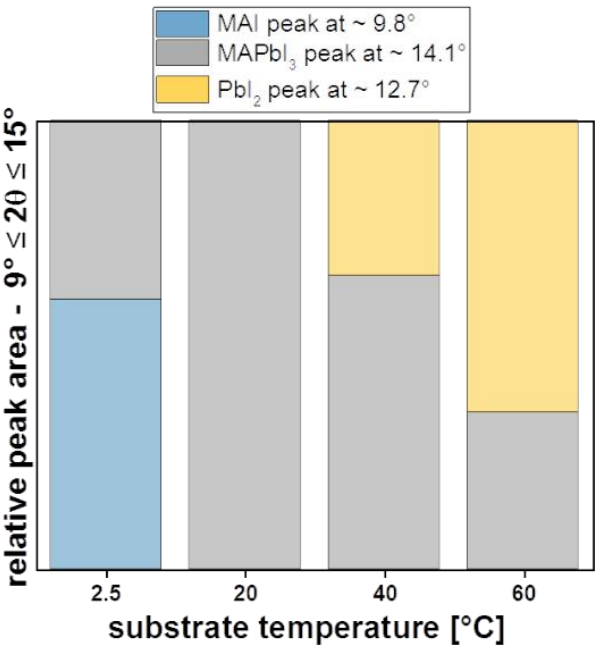

d)

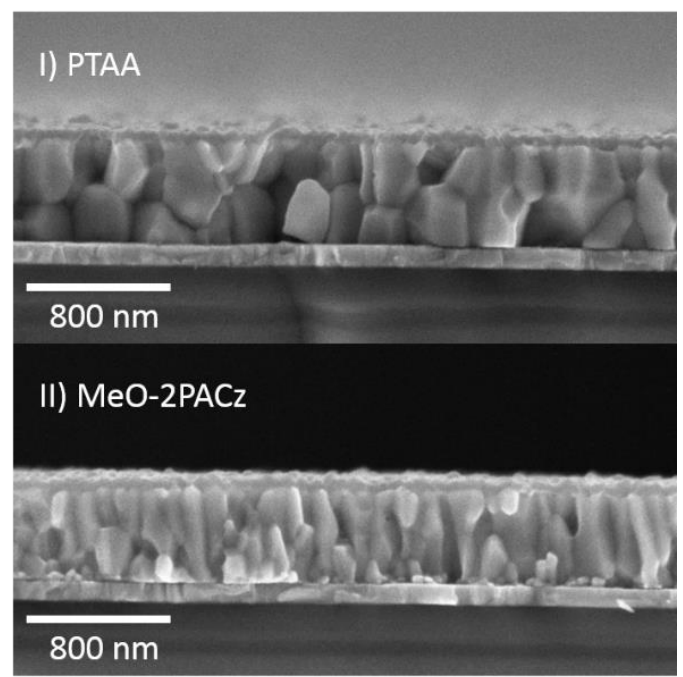

Figure 3: a) Normalised XRD patterns of co-evaporated films on PTAA deposited with different substrate temperatures. b) Relative peak areas of characteristic reflexes from a) for $\mathrm{MAI}, \mathrm{MAPbI}_{3}$ and $\mathrm{PbI}_{2}$. c) Normalised XRD patterns of films prepared on PTAA and $\mathrm{MeO}-2 \mathrm{PACz}$ at $20^{\circ} \mathrm{C}$, showing a different phase composition between PTAA $\left(\mathrm{MAPbI}_{3}\right)$ and $\mathrm{MeO}-2 \mathrm{PACz}\left(\mathrm{MAPbI}_{3}+\mathrm{PbI}_{2}\right)$. d) SEM cross section images showing different morphology for films prepared in the same evaporation process on PTAA and MeO-2PACz.

\section{Substrate temperature limits for Co-Evaporation}

Since the adhesion of MAI decreases strongly with increasing temperature, the deposition of stoichiometric $\mathrm{MAPbI}_{3}$ at high substrate temperatures is limited. At elevated temperatures, the incorporation of MAI is hindered. To compensate this problem, extremely high MAI rates would be required. Such high rates are difficult to control and require high temperatures, which can cause decomposition of MAI. Furthermore, the capacity of MAI crucibles can already become restrictive for the large quantities of MAI. Above a substrate temperature of $60{ }^{\circ} \mathrm{C}$ it is not possible to provide a sufficiently high MAI rate in our setup to compensate for the poor adhesion of MAI to the substrate. For lower substrate temperatures, only a reduced MAI rate is required, which can easily be achieved and controlled.

However, at substrate temperatures below $-25^{\circ} \mathrm{C}$ a further limitation for co-evaporation was found. After deposition at such low substrate temperature, we observed that the films were not black or brown after deposition, but yellow. These yellow films could be converted into black films by annealing at $40{ }^{\circ} \mathrm{C}$. Figure 4a shows a photograph of the films prepared at $-30{ }^{\circ} \mathrm{C}$ 
substrate temperature before and after annealing. To study this conversion process, the photoluminescence (PL) signal of a sample deposited at low temperature was recorded while heating it from below room temperature (RT) to $50{ }^{\circ} \mathrm{C}$. For this purpose, an averaged PL spectrum was recorded every 5 seconds (Fig. 4b). The cold sample is showing nearly no (evaporated) $\mathrm{MAPbI}_{3}$-typical PL emission at around $750 \mathrm{~nm}$. While heating up passively to ambient temperature the PL intensity is slightly increasing, which indicates the beginning transformation to perovskite. With increasing temperature by active heating towards $50^{\circ} \mathrm{C}$, the PL intensity raises drastically. At the moment of the complete conversion to perovskite after 680 seconds, the maximum PL intensity is reached at ca. $40{ }^{\circ} \mathrm{C}$. Surprisingly, afterwards the rising temperature causes a slight decrease in intensity. This PL decrease is discussed and attributed to enhanced exciton-phonon interaction at elevated temperatures. ${ }^{53-54}$ To understand the changes of the crystal phase during the heating-induced transition of the unreacted precursor-rich film by co-evaporation at very low substrate temperature, a sample was further analysed by XRD. Figure 4c shows the XRD pattern of a film prepared on PTAA before (below RT) and after annealing $\left(40{ }^{\circ} \mathrm{C}\right)$. Before annealing no crystalline phase is detected and only the amorphous background of the inert sample holder is present. This result is rather unexpected, as the two precursor materials $\mathrm{PbI}_{2}$ and MAI show crystalline phases even when they are individually deposited at low temperatures. This leads to the conclusion that the co-evaporation process at very low temperatures does not lead to a finely distributed mixture of crystalline precursors, but that MAI and $\mathrm{PbI}_{2}$ interfere with each other and are therefore constrained to form an amorphous yet unreacted film. Interestingly, after annealing, the XRD pattern shows a significant excess of lead iodide, although one would expect a high inclusion of MAI at low temperature. However, since there is no reaction between the two precursors, the usual increase in the tooling factor of MAI in co-evaporation seems to be absent. Therefore, the previously at ambient substrate temperatures determined rate ratios lead to an excess of $\mathrm{PbI}_{2}$. A schematic summary of the changes in tooling factor over the temperature range from -30 to $60{ }^{\circ} \mathrm{C}$ is shown in Figure S7 in the Supporting Information.

Our results suggest that for perovskite deposition two factors play a crucial role. First, at low substrate temperatures the complete conversion of the precursors to perovskite is hindered. Second, at elevated temperatures the limited MAI inclusion into the absorber film is the main restriction. When choosing the substrate temperature, it is therefore important to find a compromise between sufficient incorporation of MAI into the film and an efficient conversion of the precursor materials to perovskite.

a)

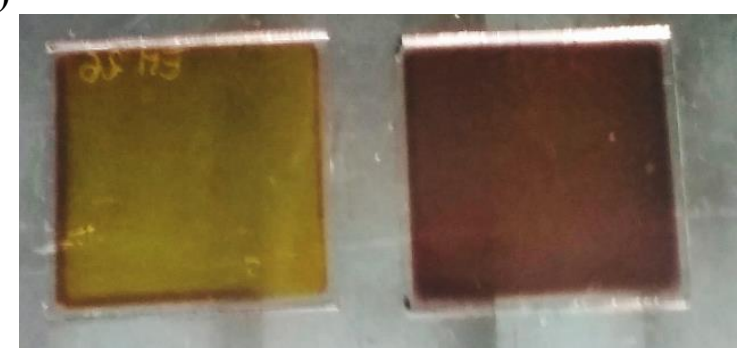


b)

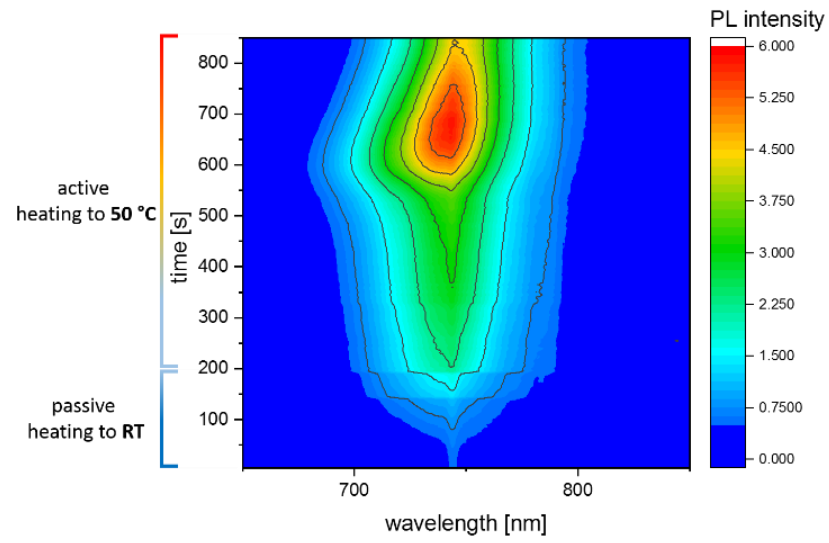

c)

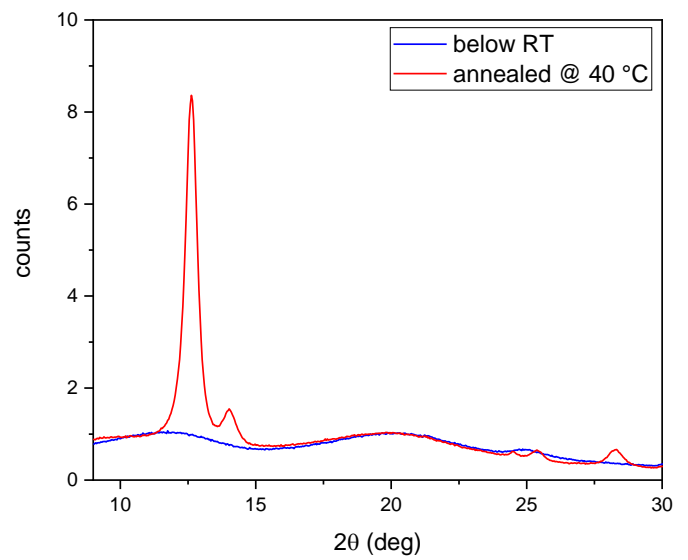

Figure 4: a) Picture of a co-evaporated film prepared at low substrate temperature direct after deposition (left) and after annealing at $40{ }^{\circ} \mathrm{C}$ (right). b) Development of the PL signal of a sample deposited at low substrate temperature during the two-phase annealing process. c) XRD measured below RT (blue) and after annealing at $40^{\circ} \mathrm{C}$ (red).

\section{Perovskite solar cell performance}

In the following, we investigate the influence of the substrate temperature during co-evaporation of the perovskite absorber on the resulting $\mathrm{p}-\mathrm{i}-\mathrm{n}$ solar cell power conversion efficiency. For this, we prepared devices on the HTLs PTAA and MeO-2PACz at different substrate temperatures. The temperature range was chosen between $2.5^{\circ} \mathrm{C}$ and $40{ }^{\circ} \mathrm{C}$, ensuring that the perovskite is already formed during deposition without further post-annealing after evaporation. In Figure 5 the p-i-n solar cell architecture and the molecular structure of the used HTLs are displayed. In comparison to the n-i-p architecture, the p-i-n design, in which the perovskite absorber is deposited directly on the HTL, offers several advantages such as low current-voltage hysteresis ${ }^{55}$ the possibility of low-temperature fabrication and the thin HTLs that can be processed without any dopants. ${ }^{8}$ Furthermore, the $\mathrm{p}-\mathrm{i}-\mathrm{n}$ architecture is an excellent candidate for application in monolithic perovskite-silicon tandem solar cells. ${ }^{38-39}$

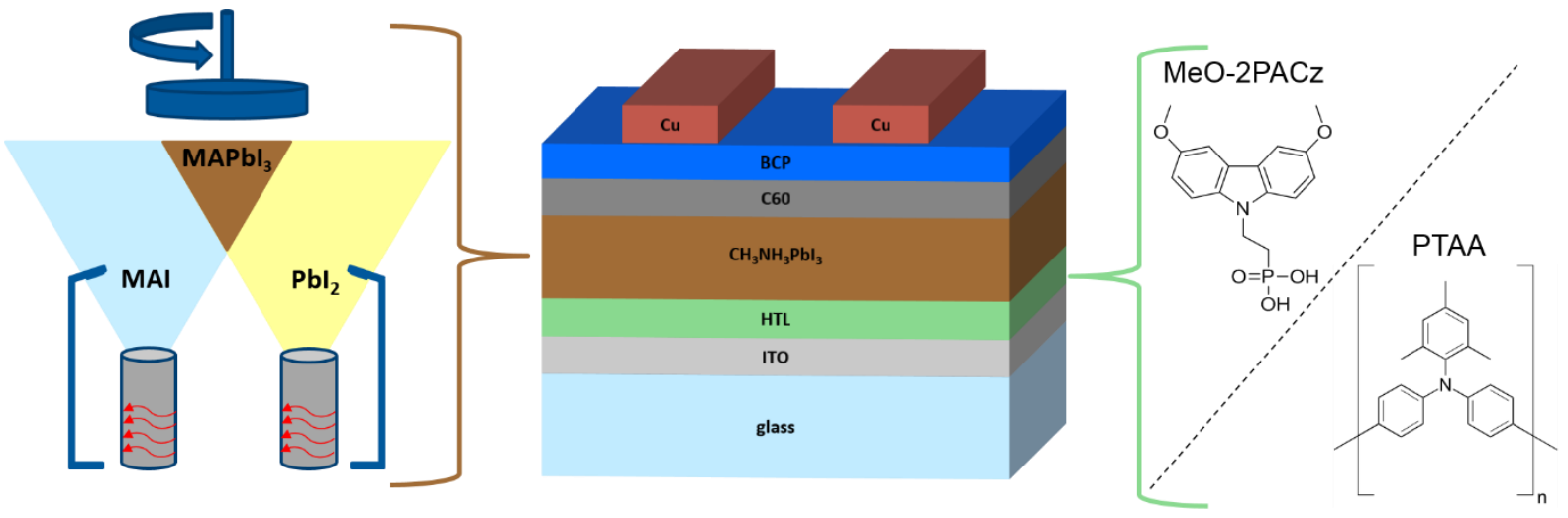

Figure 5: Schematic of the co-evaporation process (left) and the investigated p-i-n solar cell architecture (middle) prepared on the different hole-transport layers PTAA and $\mathrm{MeO}-2 \mathrm{PACz}$ (right).

As previously demonstrated, the substrate temperature can change the composition of the resulting perovskite material. Therefore, several $\mathrm{MAI}$ to $\mathrm{PbI}_{2}$ ratios were tested in parallel for each substrate temperature. Based on the above gained knowledge, we fabricated perovskite solar cells under the following conditions: three different substrate temperatures $\left(2.5^{\circ} \mathrm{C}, 20^{\circ} \mathrm{C}\right.$, and $40{ }^{\circ} \mathrm{C}$ ), two different HTLs (PTAA, MeO-2PACz) and various MAI rates (ranging from $2.2 \AA \mathrm{s}^{-1}$ to $\left.4.4 \AA \mathrm{As}^{-1}\right)$. The $\mathrm{PbI}_{2}$ rate was kept constant at $1.4 \AA \mathrm{s}^{-1}$. 
For every combination of temperature, rate ratio and HTL we prepared 12 solar cells. Figure 6 shows the statistics of the measured solar cell PCE in J-V scan (reverse and forward scan) under simulated AM 1.5g illumination. The corresponding performance parameters open-circuit voltage $\left(\mathrm{V}_{\mathrm{oc}}\right)$, short circuit current density $\left(\mathrm{J}_{\mathrm{sc}}\right)$, and fill factor $(\mathrm{FF})$ can be found in Figures $\mathbf{S 8}$, S9, and $\mathbf{S 1 0}$ respectively.

Comparing the HTLs PTAA (a) and MeO-2PACz (b), it is noticeable that for all substrate temperatures and all rates, higher PCEs are achieved with MeO-2PACz. This can be partly explained by the already shown strongly reduced non-radiative recombination at the interface to $\mathrm{MeO}-2 \mathrm{PACz}^{45}$ and partly by the change in growth resulting in a different perovskite quality between PTAA and SAM, observed in this study. The differences in morphology may also explain why the fill factor shown in Figure S10 is also significantly higher on $\mathrm{MeO}-2 \mathrm{PACz}$ than on PTAA. The maximum power conversion efficiency on PTAA of $14.3 \%$ is rather low compared to the recently published PCE of $17.4 \%$ that was mainly enabled by a higher FF. ${ }^{33}$ This discrepancy may result from the different top contact $\left(\mathrm{C}_{60} / \mathrm{BCP} / \mathrm{Cu}\right.$ vs. $\left.\mathrm{PCBM} / \mathrm{Al}\right)$ or the fact that the PTAA thickness was not specifically optimised for the co-evaporated perovskite.

For all three substrate temperatures decent solar cell PCEs ranging from $10 \%$ to $18 \%$ can be achieved for optimised rate ratios. For both PTAA and MeO-2PACz, the optimum in terms of PCE shifts with increasing substrate temperature to higher MAI rates. This is in line with our results of reduced tooling factor of MAI at elevated temperatures as explained above. For films deposited on PTAA and MeO-2PACz at $2.5^{\circ} \mathrm{C}$ the maximum PCE can be achieved with a MAI rate of 2.6 $\mathrm{ss}^{-1}$, whereby more MAI (e.g. 3.0 $\AA^{-1}$ ) results in a drastic drop of performance. This reduction indicates that the film contains too much MAI, which leads to a significant decrease of the $\mathbf{J}_{\mathrm{sc}}$. (See Figure $\mathbf{S 9}$ in the Supporting Information). For spin coated perovskite films a strong $\mathrm{J}_{\mathrm{sc}}$ reduction was observed starting from $6 \%$ MAI excess. ${ }^{56}$ At $20{ }^{\circ} \mathrm{C}$ the maximum PCE is achieved for both HTLs with a rate of $2.9 \AA^{-1}$. Interestingly, according to our XRD results, this does not correspond to the stoichiometric $\mathrm{MAPbI}_{3}$ case but to a certain excess of $\mathrm{PbI}_{2}$. As already shown for solution-based perovskite solar cells, an excess of $\mathrm{PbI}_{2}$ can be beneficial and lead to a reduced recombination via defects. ${ }^{57-58}$ For our solar cells, this is reflected in an increasing $\mathrm{V}_{\text {oc }}$ with rising $\mathrm{PbI}_{2}$ excess, see Figure S8. At $40{ }^{\circ} \mathrm{C}$ the highest $\mathrm{PCE}$ is obtained with a rate of $4.2 \mathrm{As}^{-1}$ for solar cells prepared on PTAA. For MeO-2PACz at $40{ }^{\circ} \mathrm{C}$ substrate temperature, it is difficult to determine an optimum, since the power conversion efficiencies are comparable for all MAI rates.

In general, at higher substrate temperatures, the influence of the rate variation on the PCE seems to be less pronounced. This becomes particularly clear when comparing the solar cells prepared at $2.5^{\circ} \mathrm{C}$ and $40{ }^{\circ} \mathrm{C}$ on $\mathrm{MeO}-2 \mathrm{PACz}$. While at $2.5^{\circ} \mathrm{C}$ a change in the MAI rate of $0.4 \mathrm{As}^{-1}$ (e.g. from 2.6 $\AA^{-1} s^{-1}$ to $3.0 \AA \mathrm{As}^{-1}$ ) leads to a significant loss of PCE, the power conversion efficiency is rather unaffected by a change in the MAI rate of $0.4 \AA \mathrm{As}^{-1}$ (e.g. from $3.8 \AA \mathrm{s}^{-1}$ to $4.2 \AA \mathrm{As}^{-1}$ ) at $40{ }^{\circ} \mathrm{C}$ substrate temperature. A possible explanation could be that at higher temperatures more energy is available for the conversion into the perovskite phase and therefore the formation of undesired kinetically stabilised phases is reduced. The same trend can be seen for solar cells prepared on PTAA, even though it is not as significant as on MeO-2PACz.

Overall, we were able to achieve the highest solar cell PCEs with a substrate temperature of $2.5^{\circ} \mathrm{C}$ for PTAA and much higher PCEs at $20^{\circ} \mathrm{C}$ when using MeO-2PACz. The higher temperature ensures that sufficient MAI is incorporated and still enough thermal energy is available for the conversion to the perovskite phase. Furthermore, our results indicate that in addition to temperature and rate, the HTL covering the substrate is a key factor determining the quality and reproducibility of co-evaporated perovskite solar cells. 

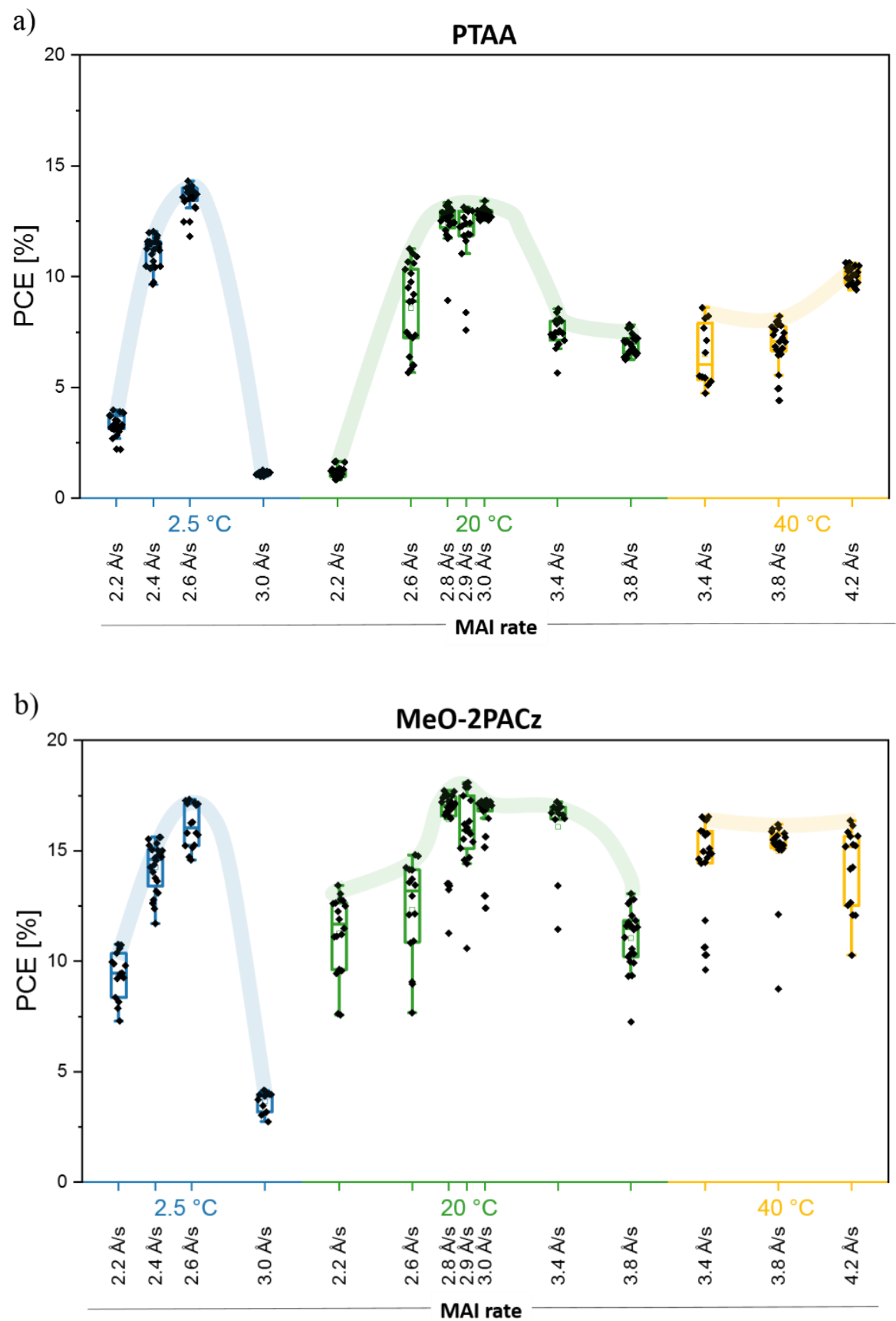

Figure 6: Box plot of power conversion efficiency (PCE) extracted from J-V scans (reverse and forward) measured under simulated AM 1.5g illumination for solar cells prepared at different substrate temperatures and MAI rates on a) PTAA and b) MeO-2PACz. For the different substrate temperatures several MAI rates were tested as indicated, while the lead iodide rate was kept constant.

The coloured lines are a guide to the eye and are designed to help interpret the trend of the results.In order to further improve the power conversion efficiency, we took the results of temperatures test into account and prepared devices on $\mathrm{MeO}-2 \mathrm{PACz}$ with a small excess of lead iodide. Furthermore, we increased perovskite absorber layer thickness to improve the photocurrent response in the long wavelength range and added a sodium fluoride antireflection coating to further increase the PCE. Figure 7 shows the current-voltage characteristic (J-V curve) under simulated AM1.5G illumination of this optimised solar cell and Table 2 displays the corresponding performance values. The device shows virtually no hysteresis and reaches a stabilised power conversion efficiency of $20.6 \%$ when tracking in maximum power point (MPP) for 20 minutes as displayed in the inset of Figure 7a. 
Due to extremely thin (one layer of molecules) HTL MeO-2PACz, the solar cell exhibits low parasitic absorption losses, which is also reflected in the high external quantum efficiency, especially in the wavelength range between 300 and $400 \mathrm{~nm}$ (Fig. 7b). The sodium fluoride antireflection coating, which was deposited on the glass side of the device to reduce reflection losses, assists in achieving a photocurrent from integration of the EQE spectra of $22.3 \mathrm{~mA} / \mathrm{cm}^{2}$, matching well with the Jsc under simulated AM $1.5 \mathrm{~g}$ measurement of $22.4 \mathrm{~mA} / \mathrm{cm}^{2}$. The absorption and thereby the total reflection of the device stack is influence by thin-film interferences. In comparison to other PSCs the interferences might be more pronounced, as the evaporated perovskite surface is very smooth and therefore the interference is not hampered by e.g. rough fluorine-doped tin oxide (FTO) or solution processed perovskite films. Due to these higher reflection losses the EQE is decreased and shows some deepening at e.g. $650 \mathrm{~nm}$. Owing to the combination of lead iodide excess and the self-assembling monolayer $\mathrm{MeO}-2 \mathrm{PACz}$, which enables columnar grain growth and shows suited energetic alignment and strongly reduced non-radiative recombination ${ }^{45}$, a high open-circuit voltage of $1.15 \mathrm{~V}$ is achieved. This corresponds to an energetic difference of $460 \mathrm{meV}$ between $\mathrm{e}^{*} \mathrm{Voc}$ and the band gap $(1.61 \mathrm{eV})$ as determined from the inflection point of the EQE. This difference results not only from the intrinsic limitation due to radiative recombination, but is also enhanced by non-radiative losses. Non-radiative losses, which are dominated by interface recombination, have been shown to occur in particular at the perovskite/ $\mathrm{C}_{60}$ interface ${ }^{43}$. The PCE achieved in this work is comparable to the highest reported values for $n-i-p$ polarity co-evaporated PSCs ${ }^{24-25}$ and is the highest for co-evaporated $\mathrm{p}-\mathrm{i}-\mathrm{n}$ architecture. Moreover, this device architecture has the potential of easy and economically viable scaling to large areas. This is achieved by the utilisation of scalable methods for all layers involved in the solar cell structure by a combination of self-assembling monolayer (immersion or printing) and vacuum processes for all other layers.

Table 2: Photovoltaic parameters from current-voltage characteristic under AM1.5G illumination in reverse and forward scan direction and MPP tracking of the best co-evaporated p-i-n perovskite solar cell fabricated on MeO-2PACz HTL.

\begin{tabular}{c||cccc}
$\begin{array}{c}\text { Measurement } \\
\text { mode }\end{array}$ & $\begin{array}{c}\mathrm{J}_{\mathrm{sc}} \\
\mathrm{mA} / \mathrm{cm}^{2}\end{array}$ & $\begin{array}{c}\mathrm{V}_{\mathrm{oc}} \\
\mathrm{V}\end{array}$ & $\begin{array}{c}\mathrm{FF} \\
\%\end{array}$ & $\begin{array}{c}\text { PCE } \\
\%\end{array}$ \\
\hline \hline $\mathrm{J}_{\mathrm{sc}}$ to $\mathrm{V}_{\mathrm{oc}}$ & 22.43 & 1.15 & 79.6 & 20.5 \\
$\mathrm{~V}_{\mathrm{oc}}$ to $\mathrm{J}_{\mathrm{sc}}$ & 22.43 & 1.15 & 79.0 & 20.3 \\
MPP & & & & 20.6
\end{tabular}


a)

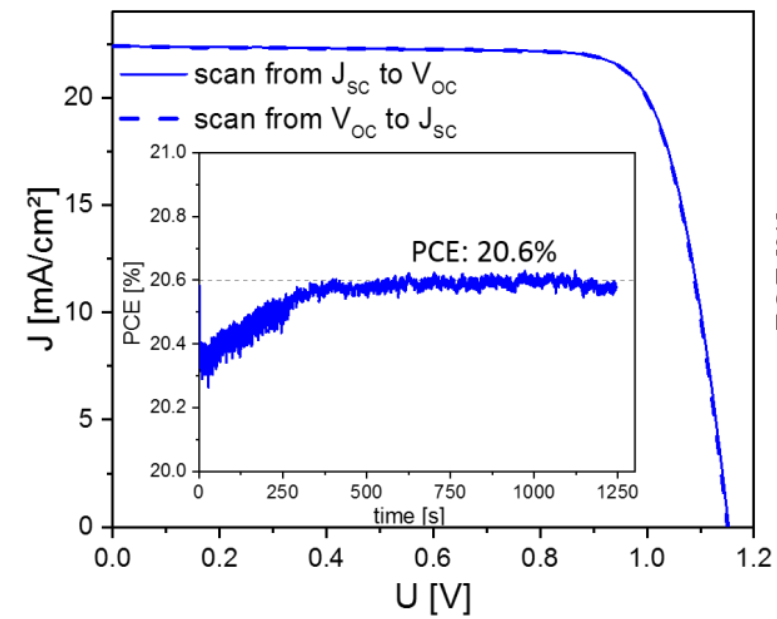

b)

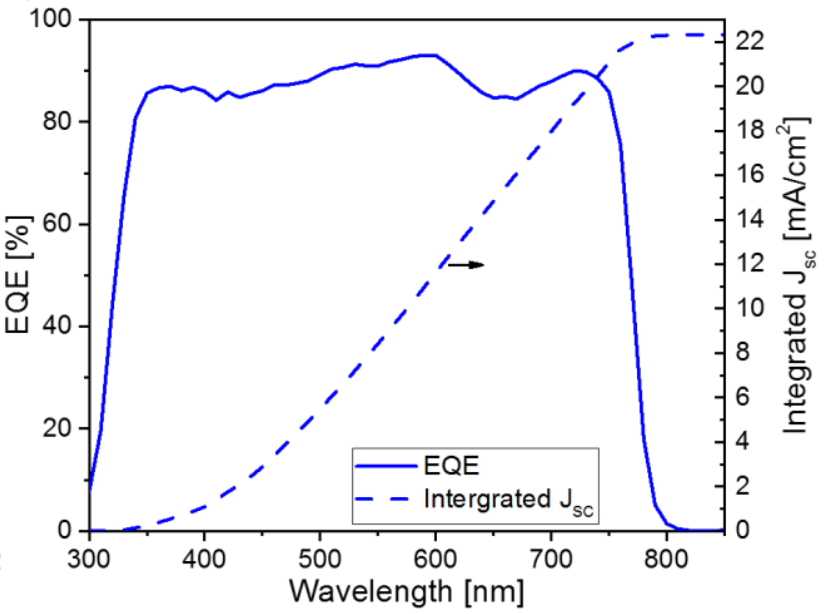

Figure 7: Solar cell performance for the best the device prepared on MeO-2PACz HTL. a) J-V curve under simulated AM 1.5G illumination with maximum power point tracking for 20 minutes in the inset. b) External quantum efficiency (EQE) SPECTRA and corresponding integration of the product with AM1.5g EQE spectrum.

\section{Conclusion}

In this work, we have investigated the influence of substrate temperature, underlying hole transporting material and precursor ratio on the morphology, composition and performance of co-evaporated p-i-n perovskite solar cells. For this, we demonstrate first how the tooling factor of the individual precursor materials $\mathrm{PbI}_{2}$ and MAI changes with the substrate temperature. While the adhesion to the substrate is largely constant for $\mathrm{PbI}_{2}$, the tooling factor for MAI is significantly reduced at higher substrate temperatures. This temperature-dependent evaporation behaviour of MAI strongly influences the co- evaporation process and can directly affect the perovskite composition. The temperature window for optimal perovskite deposition is close to room temperature. At high temperature not enough MAI for precise stoichiometry is incorporated. While at temperatures below $-25{ }^{\circ} \mathrm{C}$ the conversion of MAI with $\mathrm{PbI}_{2}$ is inhibited and an amorphous yet unreacted film is formed. We show that the appropriate choice of the HTL can have a significant effect on the process window in addition to the overall power conversion efficiency. Although both PTAA and MeO-2PACz are organic HTMs, the resulting morphology and perovskite composition vary widely, indicating a different growth mechanism. For both PTAA and MeO-2PACz solar cells, the optimum in terms of PCE shifts with increasing substrate temperature to higher MAI rates. $\mathrm{MeO}-2 \mathrm{PACz}$ is more robust against varying rate ratio and enables higher solar cell PCEs than PTAA for all substrate temperatures. In particular, $\mathrm{MeO}-2 \mathrm{PACz}$ is superior to PTAA due to its higher fill factor and increased opencircuit voltage. Through the combination of vapour-deposited perovskites and self-assembled monolayer, we were able to achieve a stabilised power conversion efficiency of $20.6 \%$ for coevaporated p-i-n solar cell architecture, which is the highest reported value to date. Furthermore, the used processes are suitable to be adapted economically on large areas. 


\section{Acknowledgements}

The authors thank T. Lußky, H. Heinz, M. Gabernig, C. Klimm, C. Ferber, M. Muske (Institute for Silicon Photovoltaics) and Tobias Henschel (PVcomB) for technical assistance. For XRD measurements, the X-Ray CoreLab, K. A. Mazzio and R. Gunder are acknowledged. We thank A. Merdasa and K. Hirselandt for the support with the insitu PL setup. The authors acknowledge funding from the Federal Ministry of Education and Research (BMBF) for funding of the Young Investigator Group Perovskite Tandem Solar Cells within the program "Materialforschung für die Energiewende" (grant no. 03SF0540), the Helmholtz Association within the HySPRINT Innovation lab project, and the HyPerCells joint Graduate School.

\section{References}

1. NREL, Best Research-Cell Efficiencies. Best Research-Cell Efficiencies: 2020.

2. Assadi, M. K.; Bakhoda, S.; Saidur, R.; Hanaei, H., Recent progress in perovskite solar cells. Renew. Sust. Energ. Rev. 2018, 81, 2812-2822.

3. $\quad$ Kazim, S.; Nazeeruddin, M. K.; Grätzel, M.; Ahmad, S., Perovskite as Light Harvester: A Game Changer in Photovoltaics. Angewandte Chemie International Edition 2014, 53 (11), 2812-2824.

4. Wang, Z.; Shi, Z.; Li, T.; Chen, Y.; Huang, W., Stability of Perovskite Solar Cells: A Prospective on the Substitution of the A Cation and X Anion. Angewandte Chemie International Edition 2017, 56 (5), 1190-1212.

5. De Wolf, S.; Holovsky, J.; Moon, S.-J.; Löper, P.; Niesen, B.; Ledinsky, M.; Haug, F.-J.; Yum, J.-H.; Ballif, C., Organometallic Halide Perovskites: Sharp Optical Absorption Edge and Its Relation to Photovoltaic Performance. The Journal of Physical Chemistry Letters 2014, 5 (6), 1035-1039.

6. $\quad$ Xing, G.; Mathews, N.; Sun, S.; Lim, S. S.; Lam, Y. M.; Grätzel, M.; Mhaisalkar, S.; Sum, T. C., Long-Range Balanced Electron- and Hole-Transport Lengths in Organic-Inorganic CH3NH3PbI3. Science 2013, 342 (6156), 344.

7. Huang, J.; Yuan, Y.; Shao, Y.; Yan, Y., Understanding the physical properties of hybrid perovskites for photovoltaic applications. Nature Reviews Materials 2017, 2 (7), 17042.

8. Zuo, C. T.; Bolink, H. J.; Han, H. W.; Huang, J. S.; Cahen, D.; Ding, L. M., Advances in Perovskite Solar Cells. Advanced Science 2016, 3 (7).

9. Jeon, N. J.; Noh, J. H.; Yang, W. S.; Kim, Y. C.; Ryu, S.; Seo, J.; Seok, S. I., Compositional engineering of perovskite materials for high-performance solar cells. Nature 2015, 517 (7535), 476-+.

10. de Vos, A., Detailed balance limit of the efficiency of tandem solar cells. Journal of Physics D Applied Physics 1980, 13, 839-846.

11. Jošt, M.; Kegelmann, L.; Korte, L.; Albrecht, S., Monolithic Perovskite Tandem Solar Cells: A Review of the Present Status and Advanced Characterization Methods Toward 30\% Efficiency. Advanced Energy Materials 2020, 1904102.

12. Swartwout, R.; Hoerantner, M. T.; Bulović, V., Scalable Deposition Methods for Large-area Production of Perovskite Thin Films. ENERGY \& ENVIRONMENTAL MATERIALS 2019, 2 (2), 119145.

13. Liu, M.; Johnston, M. B.; Snaith, H. J., Efficient planar heterojunction perovskite solar cells by vapour deposition. Nature 2013, 501 (7467), 395-398.

14. Hwang, K.; Jung, Y. S.; Heo, Y. J.; Scholes, F. H.; Watkins, S. E.; Subbiah, J.; Jones, D. J.; Kim, D. Y.; Vak, D., Toward Large Scale Roll-to-Roll Production of Fully Printed Perovskite Solar Cells. Advanced Materials 2015, 27 (7), 1241-1247.

15. Correa-Baena, J.-P.; Abate, A.; Saliba, M.; Tress, W.; Jesper Jacobsson, T.; Grätzel, M.; Hagfeldt, A., The rapid evolution of highly efficient perovskite solar cells. Energy \& Environmental Science 2017, 10 (3), 710-727.

16. Gil-Escrig, L.; Momblona, C.; La-Placa, M. G.; Boix, P. P.; Sessolo, M.; Bolink, H. J., Vacuum Deposited Triple-Cation Mixed-Halide Perovskite Solar Cells. Advanced Energy Materials 2018, 8 (14). 
17. Abzieher, T.; Schwenzer, J. A.; Moghadamzadeh, S.; Sutterluti, F.; Hossain, I. M.; Pfau, M.; Lotter, E.; Hetterich, M.; Richards, B. S.; Lemmer, U.; Powalla, M.; Paetzold, U. W., Efficient AllEvaporated pin-Perovskite Solar Cells: A Promising Approach Toward Industrial Large-Scale Fabrication. Ieee Journal of Photovoltaics 2019, 9 (5), 1249-1257.

18. Momblona, C.; Malinkiewicz, O.; Roldan-Carmona, C.; Soriano, A.; Gil-Escrig, L.; Bandiello, E.; Scheepers, M.; Edri, E.; Bolink, H. J., Efficient methylammonium lead iodide perovskite solar cells with active layers from 300 to $900 \mathrm{~nm}$. APL Mater. 2014, 2 (8), 7.

19. Kohnen, E.; Jost, M.; Morales-Vilches, A. B.; Tockhorn, P.; Al-Ashouri, A.; Macco, B.; Kegelmann, L.; Korte, L.; Rech, B.; Schlatmann, R.; Stannowski, B.; Albrecht, S., Highly efficient monolithic perovskite silicon tandem solar cells: analyzing the influence of current mismatch on device performance. Sustainable Energy \& Fuels 2019, 3 (8), 1995-2005.

20. Palazon, F.; Pérez-del-Rey, D.; Dänekamp, B.; Dreessen, C.; Sessolo, M.; Boix, P. P.; Bolink, H. J., Room-Temperature Cubic Phase Crystallization and High Stability of Vacuum-Deposited Methylammonium Lead Triiodide Thin Films for High-Efficiency Solar Cells. Advanced Materials 2019, 31 (39), 1902692.

21. Quarti, C.; Mosconi, E.; Ball, J. M.; D'Innocenzo, V.; Tao, C.; Pathak, S.; Snaith, H. J.; Petrozza, A.; De Angelis, F., Structural and optical properties of methylammonium lead iodide across the tetragonal to cubic phase transition: implications for perovskite solar cells. Energy \& Environmental Science 2016, 9 (1), 155-163.

22. Igual-Muñoz, A. M.; Ávila, J.; Boix, P. P.; Bolink, H. J., FAPb0.5Sn0.5I3: A Narrow Bandgap Perovskite Synthesized through Evaporation Methods for Solar Cell Applications. Solar RRL 2020, 4 (2), 1900283.

23. La-Placa, M.-G.; Guo, D.; Gil-Escrig, L.; Palazon, F.; Sessolo, M.; Bolink, H. J., Dual-source vacuum deposition of pure and mixed halide $2 \mathrm{D}$ perovskites: thin film characterization and processing guidelines. Journal of Materials Chemistry C 2020, 8 (6), 1902-1908.

24. Momblona, C.; Gil-Escrig, L.; Bandiello, E.; Hutter, E. M.; Sessolo, M.; Lederer, K.; BlochwitzNimoth, J.; Bolink, H. J., Efficient vacuum deposited p-i-n and n-i-p perovskite solar cells employing doped charge transport layers. Energy \& Environmental Science 2016, 9 (11), 3456-3463.

25. Perez-del-Rey, D.; Boix, P. P.; Sessolo, M.; Hadipour, A.; Bolink, H. J., Interfacial Modification for High-Efficiency Vapor-Phase-Deposited Perovskite Solar Cells Based on a Metal Oxide Buffer Layer. Journal of Physical Chemistry Letters 2018, 9 (5), 1041-1046.

26. Li, J.; Wang, H.; Chin, X. Y.; Dewi, H. A.; Vergeer, K.; Goh, T. W.; Lim, J. W. M.; Lew, J. H.; Loh, K. P.; Soci, C.; Sum, T. C.; Bolink, H. J.; Mathews, N.; Mhaisalkar, S.; Bruno, A., Highly Efficient Thermally Co-evaporated Perovskite Solar Cells and Mini-modules. Joule 2020.

27. Hsiao, S. Y.; Lin, H. L.; Lee, W. H.; Tsai, W. L.; Chiang, K. M.; Liao, W. Y.; Ren-Wu, C. Z.; Chen, C. Y.; Lin, H. W., Efficient All-Vacuum Deposited Perovskite Solar Cells by Controlling Reagent Partial Pressure in High Vacuum. Advanced Materials 2016, 28 (32), 7013-7019.

28. Wolter, S. J.; Steckenreiter, V.; Tatarzyn, M. C.; Wietler, T.; Niepelt, R.; Kajari-Schroder, S., Determination and influence evaluation of the acoustic impedance ratio for thermal co-evaporation. Appl. Phys. Lett. 2018, 113 (1), 4.

29. Borchert, J.; Leychuk, I.; Snoek, L. C.; Rothmann, M. U.; Haver, R.; Snaith, H. J.; Brabec, C. J.; Herz, L. M.; Johnston, M. B., Impurity Tracking Enables Enhanced Control and Reproducibility of Hybrid Perovskite Vapor Deposition. ACS Appl. Mater. Interfaces 2019, 11 (32), 28851-28857.

30. Movchan, B. A.; Demchishin, A. V., STRUCTURE AND PROPERTIES OF THICK CONDENSATES OF NICKEL, TITANIUM, TUNGSTEN, ALUMINUM OXIDES, AND ZIRCONIUM DIOXIDE IN VACUUM. Fiz. Metal. Metalloved. 28: 653-60 (Oct 1969). 1969.

31. Wang, S.; Ono, L. K.; Leyden, M. R.; Kato, Y.; Raga, S. R.; Lee, M. V.; Qi, Y., Smooth perovskite thin films and efficient perovskite solar cells prepared by the hybrid deposition method. Journal of Materials Chemistry A 2015, 3 (28), 14631-14641.

32. Bækbo, M. J.; Hansen, O.; Chorkendorff, I.; Vesborg, P. C. K., Deposition of methylammonium iodide via evaporation - combined kinetic and mass spectrometric study. RSC Advances 2018, 8 (52), 29899-29908.

33. Kottokkaran, R.; Gaonkar, H. A.; Abbas, H. A.; Noack, M.; Dalal, V., Performance and stability of co-evaporated vapor deposited perovskite solar cells. Journal of Materials Science: Materials in Electronics 2019, 30 (6), 5487-5494. 
34. Lohmann, K. B.; Patel, J. B.; Rothmann, M. U.; Xia, C. Q.; Oliver, R. D. J.; Herz, L. M.; Snaith, H. J.; Johnston, M. B., Control over Crystal Size in Vapor Deposited Metal-Halide Perovskite Films. ACS Energy Letters 2020, 5 (3), 710-717.

35. Zhang, H.; Wang, Y.; Wang, H.; Ma, M.; Dong, S.; Xu, Q., Influence of drying temperature on morphology of MAPbI3 thin films and the performance of solar cells. Journal of Alloys and Compounds 2019, 773, 511-518.

36. Namkoong, G.; Mamun, A. A.; Ava, T. T.; Zhang, K.; Baumgart, H., Impact of perovskite precursor solution temperature on charge carrier dynamics and photovoltaic performance of perovskite based solar cells. Organic Electronics 2017, 42, 228-233.

37. Ren, Y.-K.; Ding, X.-H.; Wu, Y.-H.; Zhu, J.; Hayat, T.; Alsaedi, A.; Xu, Y.-F.; Li, Z.-Q.; Yang, S.-F.; Dai, S.-Y., Temperature-assisted rapid nucleation: a facile method to optimize the film morphology for perovskite solar cells. Journal of Materials Chemistry A 2017, 5 (38), 20327-20333.

38. Bush, K. A.; Palmstrom, A. F.; Yu, Z. J.; Boccard, M.; Cheacharoen, R.; Mailoa, J. P.; McMeekin, D. P.; Hoye, R. L. Z.; Bailie, C. D.; Leijtens, T.; Peters, I. M.; Minichetti, M. C.; Rolston, N.; Prasanna, R.; Sofia, S.; Harwood, D.; Ma, W.; Moghadam, F.; Snaith, H. J.; Buonassisi, T.; Holman, Z. C.; Bent, S. F.; McGehee, M. D., 23.6\%-efficient monolithic perovskite/silicon tandem solar cells with improved stability. Nature Energy 2017, 2 (4), 17009.

39. Jäger, K.; Korte, L.; Rech, B.; Albrecht, S., Numerical optical optimization of monolithic planar perovskite-silicon tandem solar cells with regular and inverted device architectures. Opt. Express 2017, 25 (12), A473-A482.

40. Jošt, M.; Bertram, T.; Koushik, D.; Marquez, J. A.; Verheijen, M. A.; Heinemann, M. D.; Köhnen, E.; Al-Ashouri, A.; Rech, B.; Unold, T.; Creatore, M.; Lauermann, I.; Kaufmann, C. A.; Schlatmann, R.; Albrecht, S. In Highly efficient monolithic perovskite/CIGSe tandem solar cells on rough bottom cell surfaces, 2019 IEEE 46th Photovoltaic Specialists Conference (PVSC), 16-21 June 2019; 2019; pp 0738-0742.

41. Lin, R.; Xiao, K.; Qin, Z.; Han, Q.; Zhang, C.; Wei, M.; Saidaminov, M. I.; Gao, Y.; Xu, J.; Xiao, M.; Li, A.; Zhu, J.; Sargent, E. H.; Tan, H., Monolithic all-perovskite tandem solar cells with $24.8 \%$ efficiency exploiting comproportionation to suppress Sn(ii) oxidation in precursor ink. Nature Energy 2019, 4 (10), 864-873.

42. Olthof, S.; Meerholz, K., Substrate-dependent electronic structure and film formation of MAPbI3 perovskites. Scientific Reports 2017, 7 (1), 40267.

43. Stolterfoht, M.; Wolff, C. M.; Márquez, J. A.; Zhang, S.; Hages, C. J.; Rothhardt, D.; Albrecht, S.; Burn, P. L.; Meredith, P.; Unold, T.; Neher, D., Visualization and suppression of interfacial recombination for high-efficiency large-area pin perovskite solar cells. Nature Energy 2018, 3 (10), 847 854.

44. $\quad$ Luo, D.; Yang, W.; Wang, Z.; Sadhanala, A.; Hu, Q.; Su, R.; Shivanna, R.; Trindade, G. F.; Watts, J. F.; Xu, Z.; Liu, T.; Chen, K.; Ye, F.; Wu, P.; Zhao, L.; Wu, J.; Tu, Y.; Zhang, Y.; Yang, X.; Zhang, W.; Friend, R. H.; Gong, Q.; Snaith, H. J.; Zhu, R., Enhanced photovoltage for inverted planar heterojunction perovskite solar cells. Science 2018, 360 (6396), 1442.

45. Al-Ashouri, A.; Magomedov, A.; Ross, M.; Jost, M.; Talaikis, M.; Chistiakova, G.; Bertram, T.; Marquez, J. A.; Kohnen, E.; Kasparavicius, E.; Levcenco, S.; Gil-Escrig, L.; Hages, C. J.; Schlatmann, R.; Rech, B.; Malinauskas, T.; Unold, T.; Kaufmann, C. A.; Korte, L.; Niaura, G.; Getautis, V.; Albrecht, S., Conformal monolayer contacts with lossless interfaces for perovskite single junction and monolithic tandem solar cells. Energy \& Environmental Science 2019, 12 (11), 3356-3369.

46. Magomedov, A.; Al-Ashouri, A.; Kasparavičius, E.; Strazdaite, S.; Niaura, G.; Jošt, M.; Malinauskas, T.; Albrecht, S.; Getautis, V., Self-Assembled Hole Transporting Monolayer for Highly Efficient Perovskite Solar Cells. Advanced Energy Materials 2018, 8 (32), 1801892.

47. Wajid, A., Long-life quartz crystals for dielectric coatings. Surface and Coatings Technology 1993, 62 (1), 691-696.

48. Mohammed, S. I.; Al-Douri, Y.; Hashim, U.; Ahmed, N. M.; Al-Gaashani, R., Structural and optical properties of $\mathrm{PbI} 2$ nanostructures obtained using the thermal evaporation method. Can. J. Phys. 2013, 91 (10), 826-832.

49. Yang, D.; Yang, Z.; Qin, W.; Zhang, Y.; Liu, S.; Li, C., Alternating precursor layer deposition for highly stable perovskite films towards efficient solar cells using vacuum deposition. Journal of Materials Chemistry A 2015, 3 (18), 9401-9405. 
50. Wang, C.; Li, Y.; Xu, X.; Wang, C.; Xie, F.; Gao, Y., Degradation of co-evaporated perovskite thin film in air. Chemical Physics Letters 2016, 649, 151-155.

51. Ke, W.; Zhao, D.; Grice, C. R.; Cimaroli, A. J.; Fang, G.; Yan, Y., Efficient fully-vacuumprocessed perovskite solar cells using copper phthalocyanine as hole selective layers. Journal of Materials Chemistry A 2015, 3 (47), 23888-23894.

52. Kim, B.-S.; Kim, T.-M.; Choi, M.-S.; Shim, H.-S.; Kim, J.-J., Fully vacuum-processed perovskite solar cells with high open circuit voltage using MoO3/NPB as hole extraction layers. Organic Electronics 2015, 17, 102-106.

53. Savenije, T. J.; Ponseca, C. S.; Kunneman, L.; Abdellah, M.; Zheng, K.; Tian, Y.; Zhu, Q.; Canton, S. E.; Scheblykin, I. G.; Pullerits, T.; Yartsev, A.; Sundström, V., Thermally Activated Exciton Dissociation and Recombination Control the Carrier Dynamics in Organometal Halide Perovskite. The Journal of Physical Chemistry Letters 2014, 5 (13), 2189-2194.

54. Wu, K.; Bera, A.; Ma, C.; Du, Y.; Yang, Y.; Li, L.; Wu, T., Temperature-dependent excitonic photoluminescence of hybrid organometal halide perovskite films. Physical Chemistry Chemical Physics 2014, 16 (41), 22476-22481.

55. Heo, J. H.; Han, H. J.; Kim, D.; Ahn, T. K.; Im, S. H., Hysteresis-less inverted CH3NH3PbI3 planar perovskite hybrid solar cells with $18.1 \%$ power conversion efficiency. Energy \& Environmental Science 2015, 8 (5), 1602-1608.

56. Wang, Q.; Shao, Y.; Xie, H.; Lyu, L.; Liu, X.; Gao, Y.; Huang, J., Qualifying composition dependent $\mathrm{p}$ and $\mathrm{n}$ self-doping in CH3NH3PbI3. Appl. Phys. Lett. 2014, 105 (16), 163508.

57. Roldán-Carmona, C.; Gratia, P.; Zimmermann, I.; Grancini, G.; Gao, P.; Graetzel, M.; Nazeeruddin, M. K., High efficiency methylammonium lead triiodide perovskite solar cells: the relevance of non-stoichiometric precursors. Energy \& Environmental Science 2015, 8 (12), 3550-3556. 58. Bi, D.; Tress, W.; Dar, M. I.; Gao, P.; Luo, J.; Renevier, C.; Schenk, K.; Abate, A.; Giordano, F.; Correa Baena, J.-P.; Decoppet, J.-D.; Zakeeruddin, S. M.; Nazeeruddin, M. K.; Grätzel, M.; Hagfeldt, A., Efficient luminescent solar cells based on tailored mixed-cation perovskites. Science Advances 2016, $2(1), \mathrm{e} 1501170$. 